\title{
Optimasi Manajemen Rapat di Masa Pandemi Covid-19 Berbasis Aplikasi SeMaR
}

\author{
Ahmad Faisol ${ }^{1 *}$, Joseph Dedy Irawan ${ }^{1)}$, Hirarki Ardi Pratama ${ }^{1)}$ \\ ${ }^{1}$ Institut Teknologi Naisonal Malang \\ *mzfais@lecturer.itn.ac.id, \\ DOI: https://doi.org/10.21107/rekayasa.v13i3.9011
}

\begin{abstract}
The meeting activity is one of the routine and scheduled activities that is definitely carried out in every institution, as well as the ITN Malang campus. Problems arise when Covid-19 begins to plague in the city of Malang so that teaching and learning activities on campus must be closed and demanded to work from home according to government recommendations. Difficulties that arise are the way to send invitations and record the results of meetings that have not been efficient. So, it is necessary to develop an application that functions to manage meetings in the ITN Malang internal environment named SeMaR (Meeting Management System). This application was developed based on web and Android using design sprint development method. The results of the analysis and testing show that the design of applications that involve potential users can produce an application that is truly in accordance with user requirements. In addition, the use of the SeMaR application to manage meeting activities in the ITN Malang is able to optimize employee performance especially during the Covid-19 pandemic, and meeting management can be more effective and efficient.
\end{abstract}

Keywords: meeting management, efficiency, application, android, website

\section{PENDAHULUAN}

Menurut Hubber, rapat merupakan sebuah perangkat yang secara efisien dapat memfasilitasi pertukaran informasi diantara beberapa orang (Wirautama et.al, 2012). Di dalam setiap kegiatan rapat, selalu diawali dengan permasalahan yang hendak dibahas, dilanjutkan dengan penjadwalan dan penyebaran undangan bagi peserta rapat, sampai pada tahap proses rapat dan pencatatan kehadiran dan notulen.

Kampus Institut Teknologi Nasional (ITN) Malang, sebagai salah satu kampus swasta di kota Malang juga tidak lepas dari kegiatan rapat yang bahkan sudah menjadi kegiatan rutin dan terjadwal di setiap Fakultas dan Program Studi pada awal dan akhir periode semester. Namun kegiatan rapat menemui kendala di saat Covid19 mulai mewabah di wilayah Indonesia khususnya kota Malang dan sekitarnya, sehingga

\section{Article History:}

Received: Nov, 13 ${ }^{\text {th }}$ 2020; Accepted: Dec, $14^{\text {th }} 2020$ Rekayasa ISSN: 2502-5325 has been Accredited by Ristekdikti (Arjuna) Decree: No. 23/E/KPT/2019 August 8th, 2019 effective until 2023 kegiatan rapat harus dilakukan secara daring sebagai salah satu program Working From Home (Mungkasa, 2020).

Permasalahan paling mendasar ketika mengelola rapat secara daring adalah cara penyebaran atau pengiriman undangan kepada para peserta rapat. Alternatif pengiriman undangan yang selama ini digunakan adalah dengan mengirimkan undangan melalui media komunikasi seperti Email, WhatsApp, Telegram, atau aplikasi sejenisnya. Akan tetapi cara tersebut masih terasa kurang efisien dan tidak praktis karena pengelola rapat harus menyimpan kontak seluruh peserta yang terkadang tidak semuanya dimiliki. Selain itu, kesulitan berikutnya adalah pencatatan hasil rapat yang tetap harus dikirimkan satu - persatu kepada seluruh anggota rapat, belum lagi permasalahan jika terdapat materi atau dokumen yang harus disertakan selama kegiatan rapat. Hal tersebut menyebabkan pengelola rapat harus bekerja

\section{Cite this as:}

Faisol, A., Irawan, J.D \& Pratama, H.A (2020). Optimasi Manajemen Rapat di Masa Pandemi Covid-19 Berbasiskan Aplikasi SeMaR. Rekayasa, 13 (3), 284-290. doi: https://doi.org/0.21107/rekayasa.v13i3.9011

(C) 2020 Ahmad Fasiol, Joseph Dedy Irawan, Hirarki Ardi Pratama 
ekstra selama masa pandemi Covid-19 sehingga mengakibatkan pekerjaan lainnya bisa saja tertunda.

Berdasarkan permasalahan tersebut, kebutuhan terhadap sebuah aplikasi untuk mengelola rapat menjadi sangat mendesak, sehingga perlu dilakukan pengembangan dalam waktu singkat. Oleh karena itu, menggunakan metode Design Sprint dalam tahap perancangan menjadi pilihan yang tepat, karena metode ini dapat memvalidasi setiap kesalahan di awal melalui masukan dari pengguna sebelum aplikasi diimplementasikan (Prasetyo et.al., 2019) (Rokhmawati et.al., 2019) (Subagaya et.al., 2019) (Sumual et.al., 2019).

Berdasarkan data dari StatCounter Global Stats, Android merupakan sistem operasi ponsel pintar terbanyak digunakan saat ini (Faried et.al, 2017). Dalam penggunaannya Android ditunjang oleh aplikasi end-user untuk memaksimalkan kinerja dan membantu pengguna melakukan pekerjaannya (Yan, 2015). Salah satu fitur unggulan pada setiap aplikasi berbasis Mobile adalah adanya fitur Notifikasi. Fitur ini dapat menjadi layanan penting dalam membantu pengguna untuk mengelola task dan perubahan informasi pada aplikasi (Celeste, et.al, 2015), selain sebagai pengingat bagi pengguna terhadap tugas yang harus dilaksanakan (Ramadhan \& Utomo, 2014).

Pada penelitian ini, dikembangkan sebuah aplikasi berbasis Android yang berfungsi untuk mengelola kegiatan rapat dan diberi nama SeMaR (Sistem Manajemen Rapat). Aplikasi ini dirancang untuk memenuhi kebutuhan dalam mengelola kegiatan rapat di lingkungan kampus ITN Malang agar lebih efisien dan efektif.

\section{METODE PENELITIAN}

Penelitian ini dilakukan pada tahun 2020 dimana Covid-19 mulai mewabah di Indonesia, khususnya di Kota Malang. Dalam penelitian ini, kami menggunakan metode Design Sprint dalam mengembangkan konsep dan prototype aplikasi karena kebutuhan akan aplikasi tersebut yang harus diselesaikan dalam waktu singkat dengan hasil yang maksimal (Rokhmawati et.al., 2019). Dalam metode ini, terdapat enam tahap yang sangat komunikatif dan interaktif untuk menghasilkan sebuah ide dan desain yang dibutuhkan. Enam tahap tersebut yaitu understand, define, diverge, decide, prototype, dan validate (Subagya et.al., 2019). Berikut adalah penjelasan dari tahapan - tahapan tersebut:

1. Understand

Berdasarkan permasalahan yang sudah dijabarkan sebelumnya, bahwa kampus ITN Malang membutuhkan sebuah sistem yang berfungsi untuk mengelola rapat secara efisien dan efektif terutama di masa pandemi Covid-19. Maka dari itu, peneliti melakukan observasi dan wawancara dengan pegawai (karyawan dan dosen) ITN Malang sebagai pelaku atau calon pengguna pada aplikasi ini.

\section{Define}

Setelah melakukan observasi dan wawancara untuk menemukan permasalahan utama, peneliti mulai mengidentifikasi kebutuhan fungsional bahwa penyampaian undangan rapat, dokumen, dan notulen hasil rapat harus dapat tersampaikan dengan cepat baik di platform komputer pribadi (Laptop) maupun perangkat pintar (Smartphone) serta memudahkan tata kelola rapat bagi panitia. Selanjutnya, kebutuhan calon pengguna akan disusun secara sistematis dan terstruktur.

\section{Diverge}

Tahap berikutnya adalah membuat desain praantarmuka yang masih bersifat low-fidelty. Desain antarmuka yang dibuat akan ditinjau oleh dosen atau karyawan yang berpengalaman di bidangnya. Selain itu, pada tahap ini peneliti juga akan membuat storyboard untuk skenario pengalaman pengguna (User Experience) dalam menggunakan sistem yang sudah dikembangkan.

\section{Decide}

Setelah membuat desain pra-antarmuka dan melakukan peninjauan ulang dengan dosen maupun karyawan yang terkait, peneliti akan memilih dan menetapkan desain antarmuka mana yang paling cocok dan sesuai dengan kebutuhan pengguna. Tahap ini termasuk pemilihan warna yang akan diterapkan pada aplikasi.

\section{Prototype}

Berikutnya setelah menyelesaikan tahap deciding, peneliti mulai membangun pengembangan prototype sistem berdasarkan desain dan storyboard yang telah dibuat sebelumnya. Pembuatan prototype dimulai dari desain yang bersifat high-fidelity sehingga pengguna akan lebih mudah memahami bagaimana alur dan cara kerja sistem yang dikembangkan.

\section{Validate}

Setelah selesai membuat prototype dari sistem yang akan dikembangkan, tahap terakhir adalah melakukan pengujian terhadap hasil dari prototype ke 

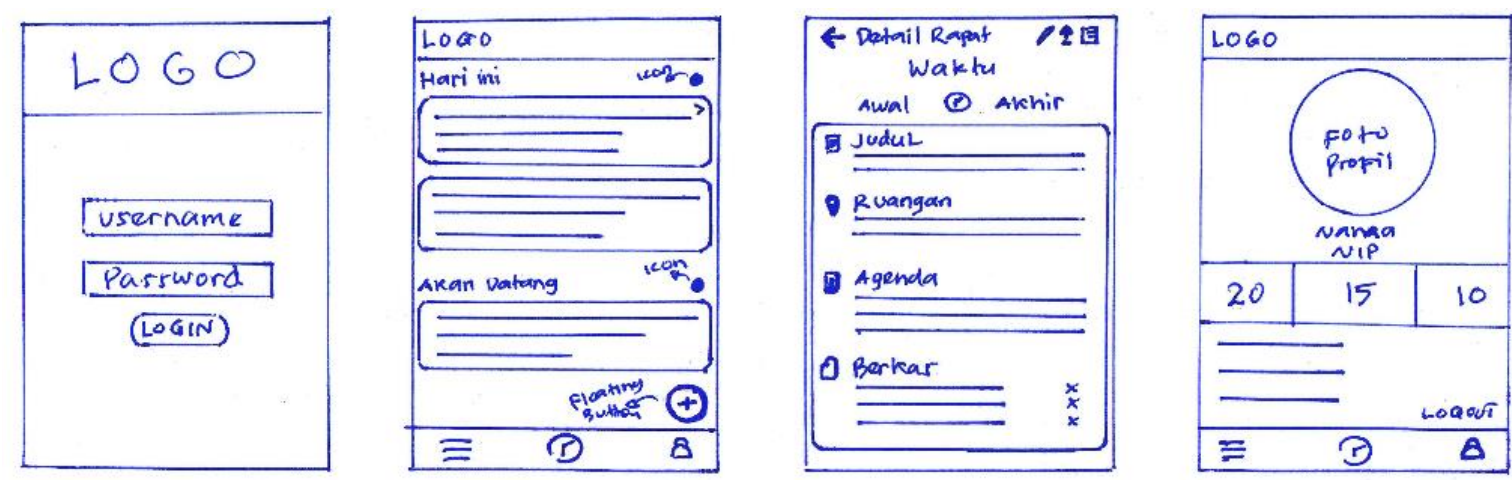

Gambar 1. . Present Solution Sketch Halaman Login, Beranda, Detil Rapat, dan Profil Pengguna
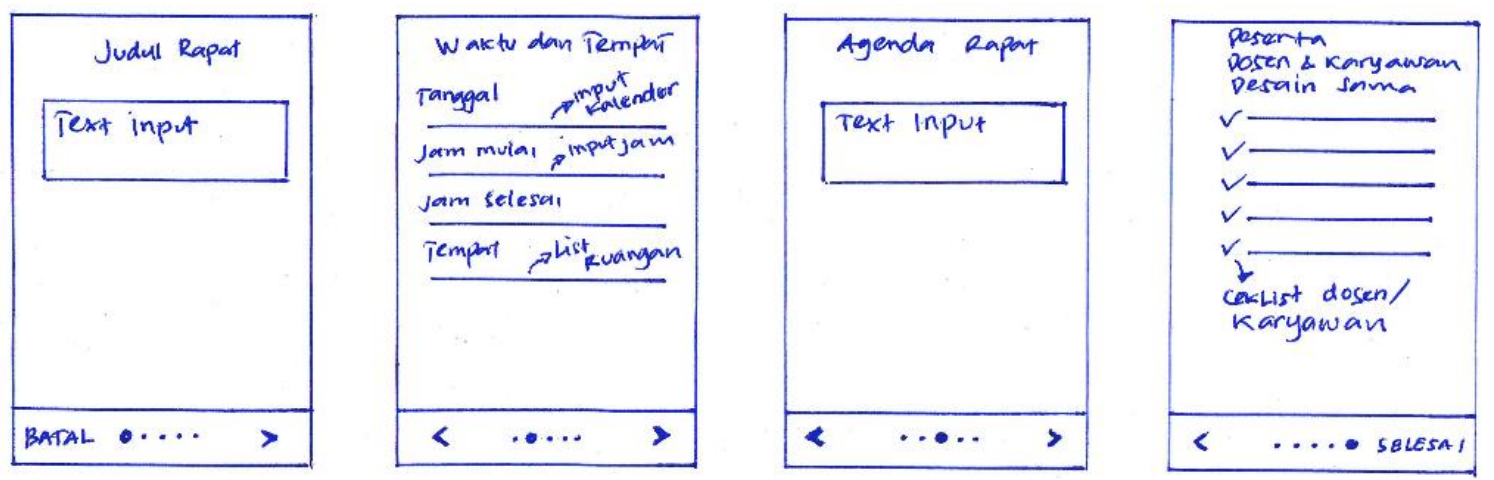

Gambar 2. Present Solution Sketch Halaman Penjadwalan Rapat

calon pengguna yaitu dosen dan karyawan di lingkungan ITN Malang. Hasil dari tahap validate ini adalah melihat bagaimana reaksi pengguna dalam memakai fitur atau sistem yang akan dikembangkan, apakah fitur atau sistem yang akan dikembangkan mempermudah pengguna atau tidak.

Dengan metode ini, proses pengembangan sebuah sistem akan lebih cepat sehingga urgensi akan kebutuhan aplikasi pengelola rapat dapat segera diterapkan di lingkungan kampus ITN Malang.

\section{HASIL DAN PEMBAHASAN}

\section{Implementasi Design Sprint}

Implementasi merupakan tahapan dalam pengembangan sebuah sistem untuk merubah hasil analisis dan desain menjadi sebuah prototype atau aplikasi. Pada tahapan ini, akan dibuat sebuah aplikasi sesuai hasil perancangan present solution sketch yang telah divalidasi sebelumnya. Untuk mempersempit ruang lingkup pembahasan, maka implementasi hanya akan membahas pengembangan aplikasi SeMaR yang berbasis Android saja.

\section{How Might We}

Pada tahap how might we peneliti mencari peluang untuk pengembangan aplikasi manajemen rapat ini. Hasil dari tahap ini adalah sebuah aplikasi yang berfungsi untuk mempermudah dan meningkatkan kinerja karyawan atau dosen dalam mengelola sebuah rapat, baik sebagai panitia maupun sebagai peserta rapat.

\section{User Interviews}

Tahap berikutnya adalah melakukan user interviews kepada calon pengguna, yaitu karyawan dan dosen, termasuk jajaran pimpinan yang ada di lingkungan kampus ITN Malang. Wawancara dilakukan dengan memberikan pertanyaan tentang apa saja yang dibutuhkan agar mengelola rapat bisa lebih efisien dan efektif serta catatan hasil rapat dapat tersimpan dengan baik. Kesimpulan dari hasil wawancara ini adalah belum ada aplikasi khusus yang benar - benar mendukung secara penuh dalam mengelola rapat di lingkungan ITN Malang.

\section{Present Solution Sketch}

Pada tahap ini, peneliti membuat gambar sketsa untuk tampilan antarmuka aplikasi yang nanti akan dikembangkan. Hasil present solution sketch dapat dilihat pada Gambar 1 dan 2. 


\section{Prototyping Real Enough}

Tahap ini menjelaskan prototype dari aplikasi SeMaR yang dirancang berdasarkan hasil sketch prototyping. Tampilan dari prototype dapat dilihat pada Gambar 3 - 6. Gambar 3 menampilkan halaman login dari aplikasi. Terdapat logo kampus ITN Malang pada bagian pojok kiri atas di halaman Login untuk memberi kesan bahwa aplikasi ini akan digunakan di lingkungan kampus ITN Malang saja. Pada halaman login ini pengguna harus menggunakan Nomor Induk Pegawai yang telah terdaftar di database ITN Malang sebagai username. Tidak ada fitur registrasi pengguna baru di halaman login, karena aplikasi ini hanya digunakan oleh dosen dan karyawan di lingkungan kampus ITN Malang saja.

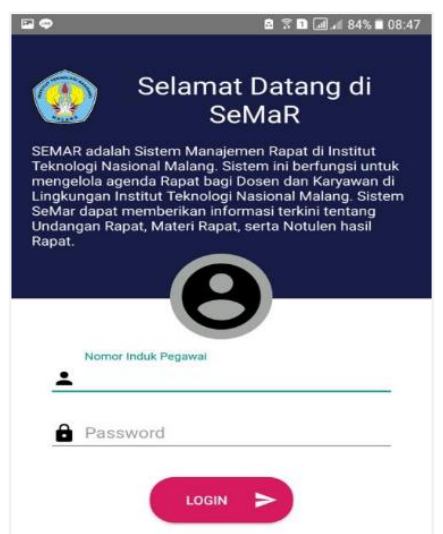

\section{Gambar 3. Tampilan Halaman Login}

Pada Gambar 4, dapat dilihat halaman beranda dan detil dari aplikasi SeMaR. Halaman beranda ini terdiri dari 3 menu yang diposisikan di bawah layar perangkat, yaitu menu Agenda, Riwayat, dan Pengguna. Halaman Agenda akan menampilkan jadwal rapat yang harus dihadiri pada hari ini dan yang akan datang. Halaman Riwayat akan menampilkan daftar riwayat rapat yang pernah diikuti selama menjadi pegawai di ITN Malang. Sedangkan halaman pengguna akan menampilkan statistik dari pengguna yang menginformasikan tentang jumlah rapat yang pernah diikuti, jumlah undangan yang telah diterima, serta jumlah kehadiran pada kegiatan rapat.

Halaman detil dari rapat dapat ditampilkan saat pengguna memilih atau menekan info rapat yang ditampilkan di halaman agenda dan histori. Terdapat 2 perbedaan fitur bagi pengguna yang login sebagai panitia atau pengelola rapat dan pengguna yang login sebagai pengguna biasa (dosen dan karyawan).
Panitia berhak untuk mengelola rapat sehingga aplikasi akan menampilkan fitur berupa tombol untuk menjadwalkan rapat, mengedit jadwal rapat, mengunggah berkas atau dokumen rapat, dan mencatat notulen hasil rapat. Sedangkan pengguna biasa hanya dapat mengakses agenda, histori, unduh berkas, dan melihat notulen saja.
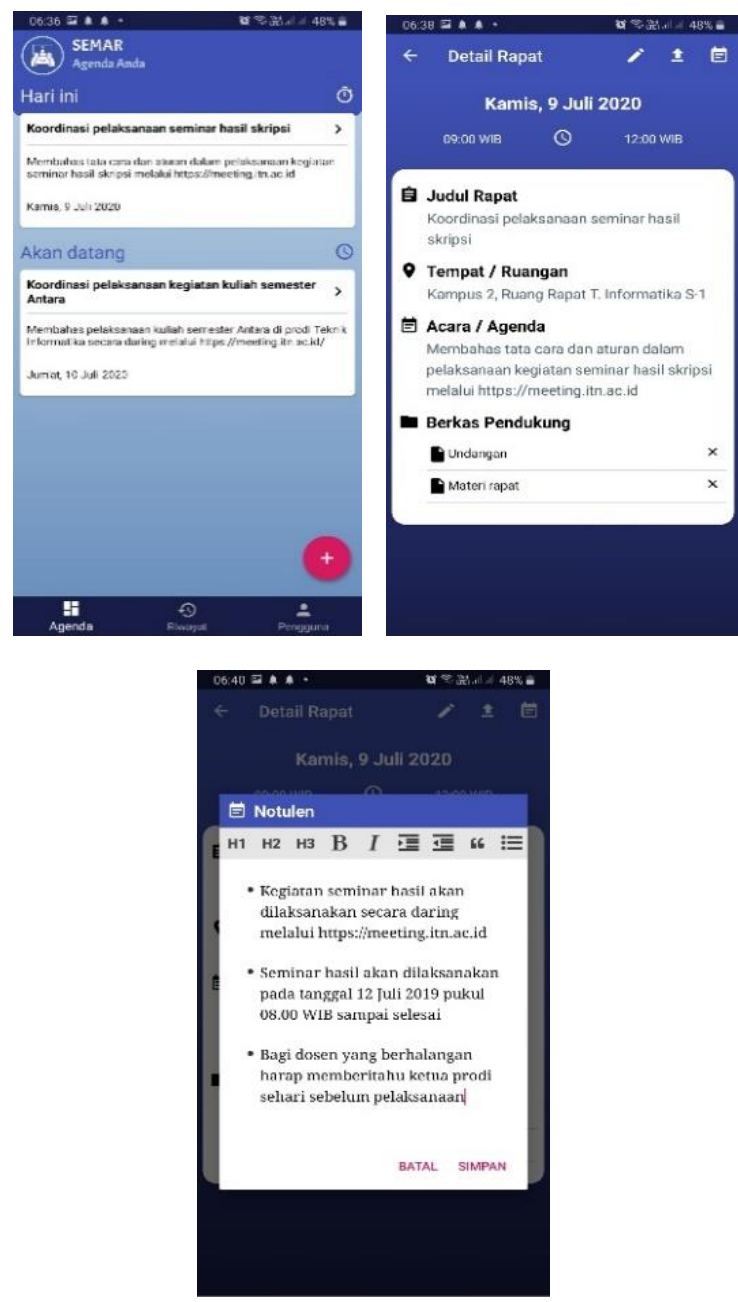

Gambar 4. Tampilan Halaman Beranda, Detail Rapat dan Notulen

Bagi pengguna yang login sebagai panitia atau pengelola rapat, maka pengguna tersebut dapat menjadwalkan rapat dengan melengkapi formulir penjadwalan rapat yang berisi judul rapat, waktu dan ruangan rapat, agenda rapat, 


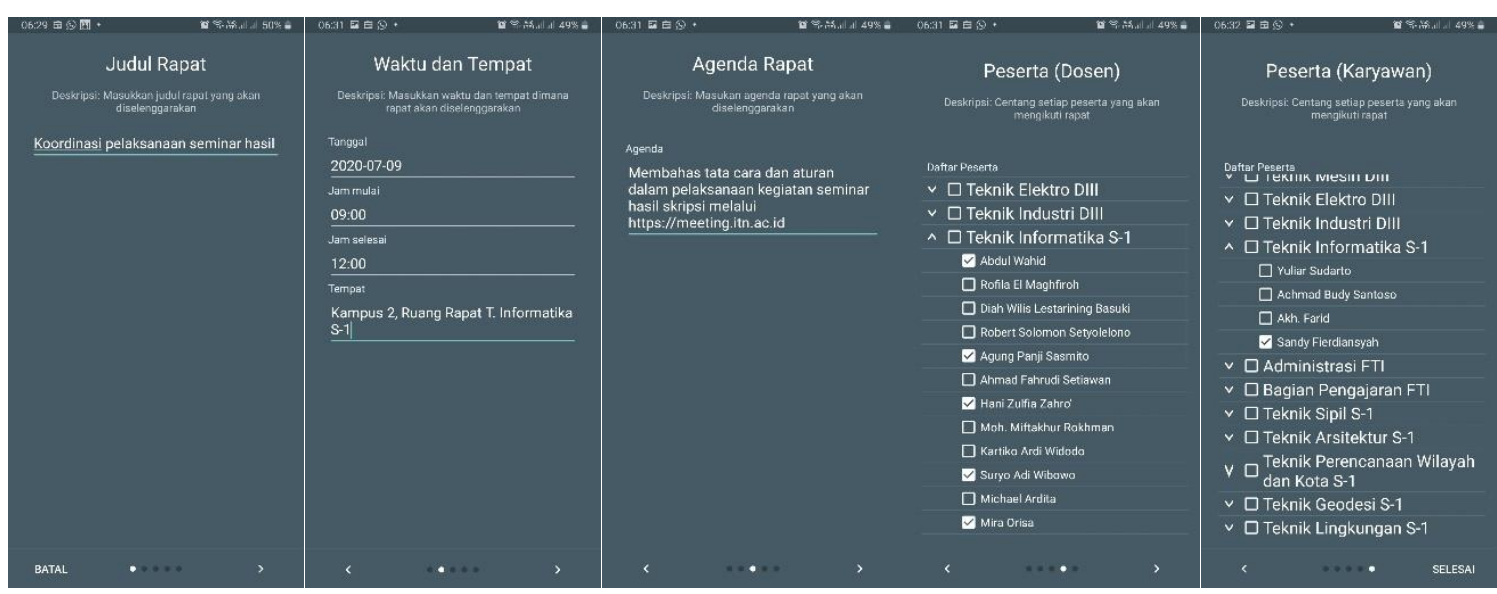

Gambar 5. Tampilan Halaman Penjadwalan Rapat

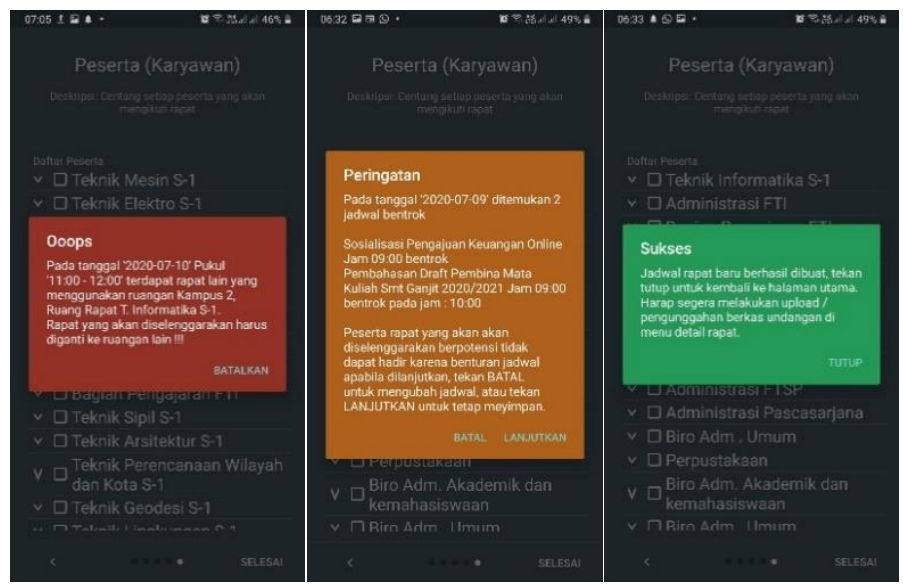

Gambar 6. Peringatan Jadwal Rapat Bentrok

dan peserta rapat (dosen dan karyawan). Proses penjadwalan rapat dapat dilihat pada Gambar 5. Jika terdapat jadwal rapat yang bentrok, baik ruangan maupun peserta rapat maka aplikasi akan menampilkan sebuah peringatan seperti yang dapat dilihat pada Gambar 6. Jika yang bentrok adalah ruangan, maka ruangan harus dirubah terlebih dahulu sebelum disimpan. Sedangkan jika yang bentrok adalah peserta, proses penyimpanan jadwal rapat masih bisa dilanjutkan dengan resiko peserta tersebut tidak bisa menghadiri rapat kecuali jika diwakilkan kepada rekannya, misal Ketua Program Studi mewakilkan kepada Sekretaris Program Studi. Sebenarnya, aplikasi SeMaR ini memiliki fitur untuk merekam dan mencetak daftar hadir peserta, akan tetapi fitur tersebut masih terbatas pada aplikasi yang berbasis web saja.

\section{Usability Study}

Pada tahap ini dilakukan pendataan kuesioner kepada beberapa dosen dan karyawan khususnya calon pengguna yang nanti akan berperan sebagai pengelola atau panitia rapat, tahap ini dilakukan untuk mengetahui respon calon pengguna terhadap aplikasi. Berdasarkan hasil kuesioner tersebut, diperoleh kesimpulan yang dapat dilihat pada Tabel 1.

\section{Sprint Conclusion: Recap and Next Steps}

Berdasarkan hasil kuesioner kepada calon pengguna, dilanjutkan dengan proses pengembangan aplikasi menjadi aplikasi yang siap pakai. Selain itu, pada tahap ini dilakukan pengujian serta merilis aplikasi SeMaR di Google Playstore agar semua pengguna di lingkungan ITN Malang bisa mengunduh aplikasi tersebut.

\section{Pengujian}

Pengujian aplikasi dilakukan dengan menggunakan metode Blackbox untuk mengetahui apakah semua fungsional sistem berjalan dengan baik. Tabel 2 menjelaskan skenario dan hasil pengujian yang telah dilakukan. 
Tabel 1. Kesimpulan Hasil Kuesioner

\begin{tabular}{lll}
\hline \hline No & \multicolumn{1}{c}{ Pertanyaan } & \multicolumn{1}{c}{ Kesimpulan } \\
\hline 1. & Bagaimana antarmuka aplikasi & Tampilan yang menarik, tidak terlalu rumit untuk dioperasikan, warna tidak \\
& manajemen rapat ini? & terlalu mencolok dan sesuai dengan ciri khas INN Malang. \\
2. & $\begin{array}{l}\text { Apakah fitur - fitur yang terdapat pada } \\
\text { aplikasi memudahkan anda dalam } \\
\text { mengelola rapat? }\end{array}$ & $\begin{array}{l}\text { Sangat membantu dalam mengelola rapat secara cepat, efektif, dan efisien. } \\
\text { Fitur penjadwalan sangat bermanfaat dalam meminimalisasi jadwal rapat }\end{array}$ \\
& $\begin{array}{l}\text { Fitur apa saja yang harus } \\
\text { dikembangkan lagi? }\end{array}$ & $\begin{array}{l}\text { Kedepannya ditambahkan fitur absensi rapat dengan face recognition, kelola } \\
\text { user profile, fitur lokasi dengan menampilkan peta lokasi rapat. }\end{array}$ \\
\hline \hline
\end{tabular}

Tabel 2. Pengujian dengan Metode Blackbox

\begin{tabular}{|c|c|c|c|}
\hline No & Skenario & Hasil yang diharapkan & Hasil Pengujian \\
\hline 1. & $\begin{array}{l}\text { Menampilkan } \\
\text { halaman Agenda } \\
\text { dan Riwayat rapat }\end{array}$ & $\begin{array}{l}\text { Agenda menampilkan jadwal rapat hari ini dan yang } \\
\text { akan datang. Sedangkan histori akan menampilkan } \\
\text { riwayat rapat yang pernah diikuti }\end{array}$ & $\begin{array}{l}\text { Halaman Agenda menampilkan daftar } \\
\text { rapat yang akan diikuti pada hari ini dan } \\
\text { yang akan datang. } \\
\text { Halaman Riwayat menampilkan daftar } \\
\text { rapat yang pernah diikuti oleh } \\
\text { pengguna }\end{array}$ \\
\hline 2. & $\begin{array}{l}\text { Pengujian hak } \\
\text { akses pengguna } \\
\text { dalam mengelola } \\
\text { rapat }\end{array}$ & $\begin{array}{l}\text { Jika yang login adalah panitia atau pengelola rapat, } \\
\text { maka akan ditampilkan tombol untuk menambah rapat, } \\
\text { mengedit rapat, mengunggah berkas, dan mencatat } \\
\text { notulen hasil rapat. Sedangkan jika yang login adalah } \\
\text { pengguna biasa (dosen dan karyawan) maka aplikasi } \\
\text { hanya akan menampilkan halaman agenda, riwayat } \\
\text { dengan tombol filter pencarian rapat, tombol untuk } \\
\text { mengunduh berkas, dan tombol untuk melihat notulen } \\
\text { hasil rapat. }\end{array}$ & $\begin{array}{l}\text { Saat login menggunakan akses sebagai } \\
\text { panitia, maka dapat mengelola rapat } \\
\text { sesuai perancangan, dimana pengguna } \\
\text { dapat menjadwalkan dan mengedit } \\
\text { rapat, mengunggah berkas, dan } \\
\text { mencatat notulen hasil rapat. } \\
\text { Saat login menggunakan akses sebagai } \\
\text { pengguna biasa, hanya terdapat fitur } \\
\text { untuk melihat agenda dan riwayat, } \\
\text { mengunduh berkas, dan melihat } \\
\text { notulen hasil rapat. }\end{array}$ \\
\hline 3. & $\begin{array}{l}\text { Menjadwalkan } \\
\text { rapat baru atau } \\
\text { merubah jadwal } \\
\text { rapat }\end{array}$ & $\begin{array}{l}\text { Setiap ada jadwal rapat baru ataupun perubahan jadwal, } \\
\text { notifikasi akan diterima oleh perangkat selama } \\
\text { pengguna terhubung dengan jaringan internet. }\end{array}$ & $\begin{array}{l}\text { Notifikasi rapat diterima dengan cepat } \\
\text { (sesuai kondisi jaringan). }\end{array}$ \\
\hline 4. & $\begin{array}{l}\text { Mengelola berkas } \\
\text { atau dokumen } \\
\text { rapat }\end{array}$ & $\begin{array}{l}\text { Panitia rapat dapat mengunggah dan mengunduh } \\
\text { dokumen rapat tanpa dibatasi jumlahnya. } \\
\text { Peserta rapat dapat mengunduh dokumen rapat dan } \\
\text { menyimpan di perangkat pengguna. }\end{array}$ & $\begin{array}{l}\text { Pengguna dapat mengelola berkas } \\
\text { atau dokumen rapat sesuai hak akses } \\
\text { yang telah diberikan. }\end{array}$ \\
\hline 5. & $\begin{array}{l}\text { Mengelola } \\
\text { notulen hasil } \\
\text { rapat }\end{array}$ & $\begin{array}{l}\text { Panitia dapat mencatat notulen hasil rapat. Sedangkan } \\
\text { peserta hanya dapat melihat hasil rapat yang sudah } \\
\text { dimasukkan oleh panitia. }\end{array}$ & $\begin{array}{l}\text { Pengguna dapat mengelola notulen } \\
\text { hasil rapat sesuai hak akses yang telah } \\
\text { diberikan. }\end{array}$ \\
\hline
\end{tabular}

\section{KESIMPULAN DAN SARAN}

Berdasarkan hasil analisis dan pengujian dapat disimpulkan bahwa desain aplikasi yang sudah diuji dan melibatkan calon pengguna dapat menghasilkan suatu aplikasi yang benar - benar sesuai kebutuhan pengguna. Penggunaan aplikasi SeMaR untuk mengelola kegiatan rapat di lingkungan kampus ITN Malang mampu mengoptimalkan kinerja pegawai terutama di masa pandemi Covid-19. Selain itu, pengelolaan rapat dapat menjadi lebih efektif dan efisien.

\section{DAFTAR PUSTAKA}

Celeste, L.P., Komlodi, A., \& Lutters, W.G. (2015). Interruptive Notifications in Support of Task Management. Int. J. Human-Computer Studies, 79, 20-34.

Faried, M.Z., Mulwinda, A., \& Primadiyono, Y. (2017). Pengembangan Aplikasi Android Bimbingan Skripsi dengan Fitur Notifikasi. Jurnal Teknik Elektro Unnes, 9(2), 74-79. 
Mungkasa. (2020). Bekerja dari Rumah (Working From Home ( WFH): Menuju Tatanan Baru Era Pandemi COVID 19. The Indonesian Journal of Development Planning, 4(2), 126-150.

Prasetyo, A., Az-Zhara, H. M., \& Brata, H.A (2019). Perancangan Aplikasi Bimbingan Skripsi Berbasis Mobile dengan menggunakan Pendekatan Design Sprint. Jurnal Pengembangan Teknologi Informasi dan Ilmu Komputer, 3(6), 5808-5816.

Ramadhan, T., \& Utomo, V.G. (2014). Rancang Bangun Aplikasi Mobile Untuk Notifikasi Jadwa Kuliah Berbasis Android (Studi Kasus: STMIK Provisi Semarang). Jurnal Teknologi Informasi dan Komunikasi, 5(2), 47-55.

Rokhmawati, R. I., Az-Zhara, H. M., \& Ramadhana, R. (2019). Perancangan User Interface Aplikasi EzyPay menggunakan Metode Design Sprint Jurnal Pengembangan Teknologi Informasi dan Ilmu Komputer, 3(9), 8831-8840.
Subagaya, K. A., Pratami, D., \& Hasibuan, M. A. (2019). Pengembangan konten E-Learning Menggunakan Design Sprint Pada Mata Kuliah Manajemen Proyek. Jurnal Integrasi Sistem Industri, 6(2), 107-106.

Sumual, H., Batmetan, J. R., \& Kambey, M. (2019). Design Sprint Methods for Developing Mobile Learning Application. 3rd UNJ International Conference on Technical and Vocational Education and Training 2018. KnE Social Science. 394-407.

Wirautama, I.K.D., Setiwan, B., \& Wibowo, R.P. (2012). Pengembangan Aplikasi Pengelolaan Rapat Studi Kasus: Jurusan Sistem Informasi Institut Teknologi Sepuluh Nopember. Jurnal Politeknik POMITS, 1-4.

Yan, Z. (2015). Encyclopedia of Mobile Phone Behavior [Online] Available: https://books.google.co.id/books?id=bIkfCg AAQBAJ\&printsec $=$ frontc over\&hl=id\#v=onepage\&q\&f=false 
Rekayasa, 13 (3): 2020 | 291 